\title{
Desain Reaktor Pengolahan Limbah Cair Laboratorium
}

\section{Design of Laboratory Liquid Waste Treatment Reactors}

\author{
Pabbenteng $^{1^{*}}$, Elisabeth Alwina ${ }^{2}$ \\ ${ }^{1}$ Jurusan Teknik Kimia, Politeknik Negeri Ujung Pandang, Indonesia \\ ${ }^{2}$ Jurusan Teknik Kimia, Politeknik Negeri Ujung Pandang, Indonesia \\ Email : ${ }^{1}$ pabbenteng@poliupg.ac.id, ${ }^{2}$ alwinahery68@gmail.com \\ Direview : 7 Februari 2020 \\ Direvisi : 12 Februari 2020
}

\begin{abstract}
Abstrak
Desain reaktor pengolahan limbah cair laboratorium bertujuan untuk mengolah limbah laboratorium sehingga ramah lingkungan berdasarkan parameter fisika dan kimia. Penurunkan konsentrasi limbah mendekati atau sesuai baku mutu limbah cair dan juga sebagai model pengolahan limbah yang memanfaatkan limbah pertanian sebagai bahan isian reaktor untuk mengolah limbah Laboratorium menjadi ramah lingkungan. Penelitian ini juga menambah nilai ekonomis terhadap limbah kulit kakao, sehingga para petani kakao mendapat penghasilan tambahan dari kulit kakao. Kondisi optimum pada desain alat ini terjadi pada laju alir 21,94 mL/detik, ketinggian adsorben $20 \mathrm{~cm}$ sehingga mampu menurunkan nilai TSS (Total Suspended Solid) dengan efisiensi sebesar 62,285\% dan TDS (Total Dissolve Suspended) dengan efisiensi sebesar 19,415 \% serta pada kondisi optimum memiliki nilai $\mathrm{pH}$ 7. Metode yang diterapkan dalam penelitian ini adalah metode filtrasi dan metode penyerapan atau adsorpsi. Aliran sampel dari bawah keatas sehingga kontak antara adsorben dan limbah dalam reaktor maksimal karena adanya pengaruh tekanan dan gravitasi.Hasil dari proses ini adanya terbentuk sedimen halus diantara adsorben.
\end{abstract}

Kata kunci : adsorpsi, limbah, reaktor, TSS, TDS.

\begin{abstract}
The design of the laboratory liquid waste treatment reactor aims to treat laboratory waste so it is environmentally friendly based on physical and chemical parameters. Reducing the concentration of waste close to or in accordance with the quality standards of liquid waste and also as a waste treatment model that utilizes agricultural waste as reactor stuffing to process laboratory waste to be environmentally friendly. This research also adds economic value to cocoa skin waste, so that cocoa farmers get additional income from cocoa shells. The optimum conditions in the design of this tool occur at a flow rate of $21.94 \mathrm{~mL} / \mathrm{sec}$, the height of the adsorbent $20 \mathrm{~cm}$ so as to reduce the value of TSS (Total Suspended Solid) with an efficiency of 62,285\% and TDS (Total Dissolve Suspended) with an efficiency of 19,415\% and at optimum conditions have a $p H$ value of 7 . The method applied in this study is the filtration method and the absorption or adsorption method. The sample flow from the bottom up so that the contact between the adsorbent and the waste in the reactor is maximal because of the influence of pressure and gravity. The result of this process is the formation of fine sediments between adsorbents.
\end{abstract}

Keywords: adsorption, waste, reactors, TSS, TDS.

DOI : 10.35970/jppl.v2i1.142

Corresponding Author : pabbenteng@poliupg.ac.id 


\section{PENDAHULUAN}

Laboratorium adalah tempat dilakukannya pengujian dan penelitian, baik fisika, kimia maupun biologi untuk memperoleh hasil yang akurat. Limbah cair laboratorium merupakan limbah yang paling berbahaya karena banyak mengandung zat

kimia yang tergolong limbah B3 yang sukar diurai oleh lingkungan. Alat pengolahan limbah laboratorium sangat dibutuhkan untuk menurunkan nilai TDS, TSS serta kandungan logam berat yang terdapat dalam limbah laboratorium tesebut sehingga bisa digunakan kembali serta aman bagi lingkungan. 
Air limbah dari laboratorium kimia dihasilkan oleh berbagai kegiatan di laboratorium, seperti mencuci peralatan gelas dan limbah kimia dari penelitian dan kegiatan praktium mahasiswa. Cairan kimia yang dibuang mengandung bahan kimia yang beracun, senyawa organik dan logam berat yang berbahaya bagi organisme hidup dan lingkungan hidup (Putra dkk., 2017). Logam berat yang terdapat dalam limbah Laboratorium berasal dari zat kimia yang digunakan dalam penelitian yang dilakukan dalam Laboratorium.

Pencemaran lingkungan adalah suatu keadaan yang terjadi karena perubahan kondisi tata lingkungan (tanah, udara dan air) yang tidak menguntungkan disebabkan oleh kehadiran benda-benda asing, sehingga lingkungan tersebut tidak berfungsi seperti semula (Fahruddin, 2017). Pencemaran lingkungan terbagi dalam 3 kategori yaitu pencemaran air, udara dan tanah. Ketiga jenis pencemaran ini memiliki sumber pencemar yang berbeda.

Kakao (Theobroma cacao L), merupakan salah satu komoditi ekspor Negara Indonesia dengan nilai jual yang cukup tinggi. Beberapa teknologi telah dikembangkan untuk mengolah kulit buah kakao menjadi pakan ternak, kompos, sebagai anti bakteri, dan produk lain untuk dimanfaatkan lebih optimal (Muliyatni dkk., 2012). Kakao merupakan tanaman daerah panas, berbunga dan berbuah sepanjang tahun. Bentuk buahnya lonjong berwarna ungu atau kuning yang bergantungan pada batangnya (Rahmaniah, 2016).

Kulit kakao juga bisa dimanfaatkan sebagai sumber nutisi alternatif hewan. Pada penelitian Sa dan Abike (2016 ), membandingkan antara kulit kakao yang difermentasi dengan kulit kakao yang tidak difermentasi. Kulit buah kakao mengandung selulosa $36,23 \%$, hemiselulosa $1,14 \%$ dan

lignin 20-27,95\%. Kandungan selulosa yang cukup tinggi pada kulit buah kakao ini yang berpotensi diolah lebih lanjut sebagai adsorben (Purnamawati dan Utami, 2014).

Kulit kakao yang telah diblender diletakkan dalam reaktor sebagai adsorben dalam penelitian ini.Kolom terbuat dari pipa PVC dengan diameter 2 inch dan panjang sekitar $50 \mathrm{~cm}$. Diameter ditentukan kolom ditentukan sebesar 2 inch dengan pertimbangan diameter rata-rata adsorben sekitar 50 mesh - 100 mesh dan diameter minimum kolom adalah 10 kali diameter adsorben untuk menghindarai efek dinding (Katherine dan Arie, 2016).

PVC (poly vinil chloride), polyetena, dan nylon termasuk jenis polimer sintetsis. Polimer sintetis adalah polimer yang dibuat dari molekul sederhana (monomer) dalam pabrik atau polimer yang dibuat dari bahan baku kimia. Sifat- sifat khas bahan polimer pada umumnya adalah produk ringan dan kuat, kemampuan cetaknya yang baik, memiliki ketahanan yang baik terhadap air dan zat kimia, umumnya bahan polimer memiliki harga yang lebih murah (Ikhsan, 2016).

Pengolahan limbah cair industri kertas menggunakan reaktor USAB (Upflow Anaerobic Sludge Blanket) dengan lumpur aktif. Reaktor ini efektif untuk limbah organik tetapi tidak efektif untuk limbah anorganik termasuk logam berat. Reaktor ini efektif pada waktu tinggal dari 10 jam - 24 jam untuk menurunkan nilai TSS dan TDS (Kristaufan dkk, 2010). Pengolahan limbah cair domestik menggunakan Reaktor MSL (Multi-soillayering). Bahan isian yang paling efektif untuk mengolah limbah cair domestik adalah zeolit dan arang tempurung kelapa. Efisiensi reaktor MSL ini untuk TSS 64,55 \% dan TDS 24,52 \%(Haribowo dkk, 2019). Berdasarkan hasil dari reaktor USAB dan MSL terhadap limbah cair memiliki kondisi optimum pada bahan isian yang berbeda. Pada penelitian ini didesain reaktor dengan model vertikal dengan bahan isian atau adsorben menggunakan kulit kakao.

Alat ini didesain dengan sistem aliran dari bawah mengalir keatas kolom penyaringan dengan bantuan tekanan dari pompa dan dilengkapi dengan katub pengatur kecepatan alir, sehingga adsorben kulit kakao tidak terbawa oleh tekanan dari pompa, sehingga kontak antara adsorben dan limbah maksimal sehingga kinerja alat optimum. Desain proses pengolahan limbah air umumnya terdiri dari proses koagulasi, flokulasi dan filtrasi. Koagulasi dan flokulasi bertujuan untuk mengurangi TSS (Hartuno dkk., 2014). Desain ini fokus pada filtrasi dengan menggunakan kulit kakao sebagai adsorben. Skema desain alat ini dapat dilihat pada Gambar 1. 


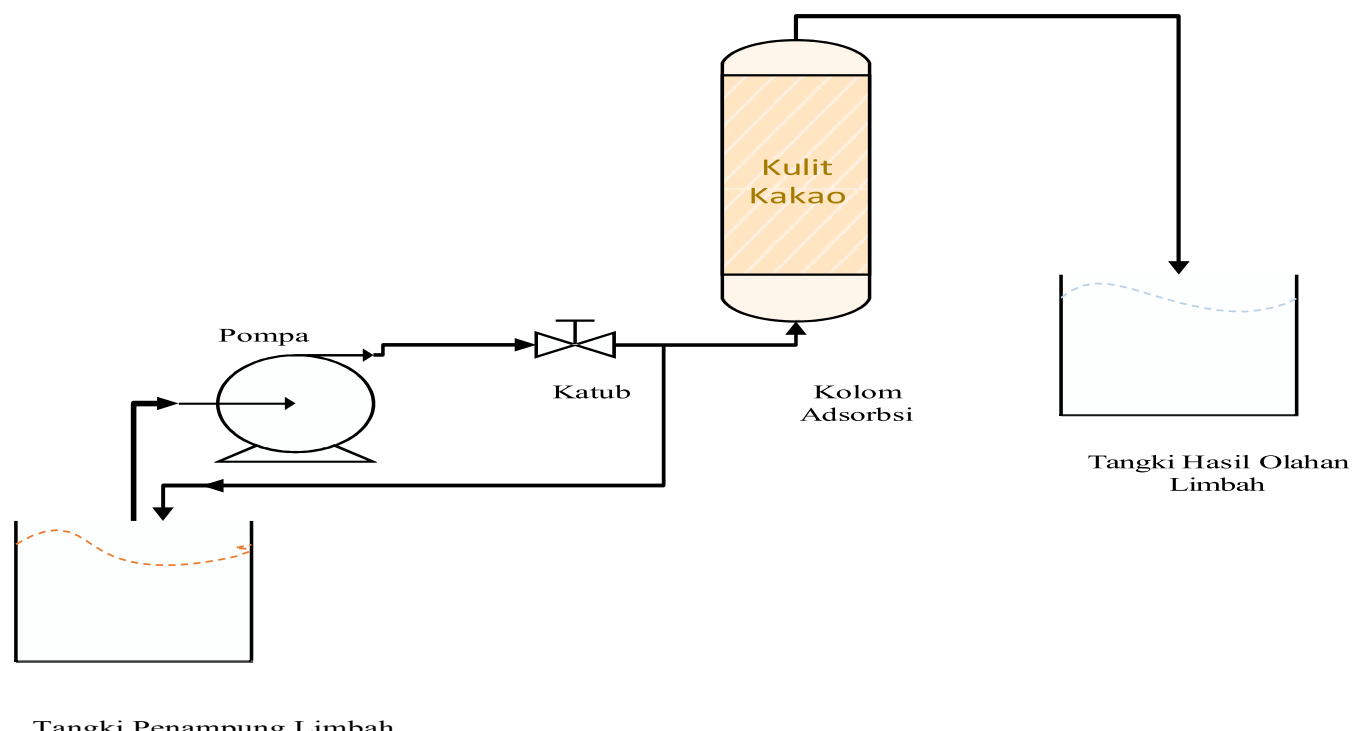

Gambar 1. Rangkaian reaktor pengolahan limbah laboratorium

Tujuan dari penelitian ini adalah menetukan kondisi optimum reaktor pengolahan limbah dengan memanfaatkan limbah pertanian kulit kakao sebagai adsorben. Penelitian ini meningkatkan nilai ekonomis kulit kakao sehingga para petani kakao memiliki pendapatan tambahan. Parameter fisika limbah Laboratorium dapat ditentukan meliputi TSS, TDS, pH, warna dan bau dengan perlakuan tinggi adsorben dan laju alir limbah Laboratorium.

\section{METODE PENELITIAN}

1.1 Waktu dan Lokasi Penelitian Penelitian dilakukan di Laboratorium Pengolahan Limbah Jurusan Teknik Kimia Politeknik Negeri Ujung Pandang, dalam kurun waktu 5 bulan yakni bulan April hingga Agustus 2019.

1.2 Alat dan Bahan Penelitian

Alat-alat yang digunakan pada penelitian ini dibagi 2 yaitu alat proses pembuatan reaktor terdiri dari gergaji, meteran, mata bor, pompa dan alat pengujian kinerja alat berdasarkan parameter fisika terdiri dari Oven merk Memmert, penampung limbah, erlen meyer vakum, corong burchner, pompa vakum, petridis, gelas kimia, timbangan analitik, pipet ukur, pipet volume, gegep, pinset, batang pengaduk, labu semprot, $\mathrm{pH}$ meter. Bahan yang digunakan terbagi 2 yaitu bahan pembuatan alat pengolah limbah terdiri dari pipa PVC 2 inch, pipa PVC $1 / 2$ inch, lem pipa, isolatip pipa, stop kran, sambungan pipa, dop, water mor, amplas, Alumnium Composite Panel (ACP) dan bahan pengujian kinerja alat berdasarkan parameter fisika terdiri dari kertas saring Whatman 41 dan aquades.

1.3 Pelaksanaan Penelitian

Reaktor terbuat dari pipa PVC diameter 2 inch dipotong sepanjang $50 \mathrm{~cm}$, dihubungkan dengan pompa melalui pipa PVC $1 / 2$ inch. Reaktor dipasang pada rangka besi yang dipasangi Alumninium Composite Panel (ACP). Reaktor didesain menggunakan bahan yang tahan terhadap air dan bahan kimia serta ringan. Laju alir diatur dengan memasang katub antara pompa dan inlet reaktor. Kulit kakao dibersihkan dikeringkan dibawah sinar matahari, sekitar 2-7 hari, lalu dipanaskan dalam oven pada suhu $105{ }^{\circ} \mathrm{C}$ sekitar 4 jam untuk mengeluarkan air dalam kulit kakao tersebut. Kulit kakao yang sudah kering di hancurkan menggunakan blender dengan ukuran sekitar 50 mesh - 100 mesh. Reaktor diisi dengan kulit kakao berukuran 50 mesh 100 mesh sebagi adsorben. Limbah yang melewati reaktor diatur kecepatannya, dan ditampung dalam penampungan air hasil olahan. Sampel limbah laboratorium 
sebelum melewati reaktor pengolahan limbah dan sesudah melewati reaktor dianalisa warna, $\mathrm{pH}$, Total Suspended Solid (TSS). Prosedur kerja alat pengolahan limbah yaitu alat pengolahan limbah dirangkai lalu adsorben kulit cokelat dimasukkan kedalam kolom adsorpsi pada ketinggian tertentu $(10 \mathrm{~cm}, 15 \mathrm{~cm}, 20 \mathrm{~cm}, 25 \mathrm{~cm}$ dan $30 \mathrm{~cm}$ ). Pompa dinyalakankan dengan mengatur laju alir limbah yang masuk kedalam kolom adsorpsi. Limbah dan hasil olahan dianalisa $\mathrm{pH}$, TSS (SNI 06- 6989-3-2004) dan TDS ( SNI 066989-27-2005 ). Penentuan $\mathrm{pH}$ menggunakan $\mathrm{pH}$ meter sehingga nilai $\mathrm{pH}$

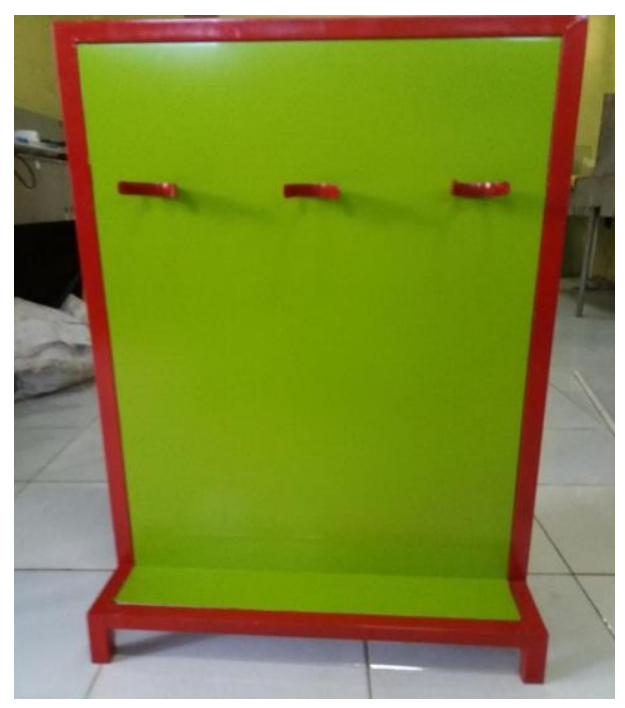

(a) terbaca pada alat $\mathrm{pH}$ meter dengan terlebih dahulu mengkalibrasi $\mathrm{pH}$ meter tersebut dengan larutan standart $\mathrm{pH} 4$ dan pH 7.

\section{HASIL DAN PEMBAHASAN}

Desain alat pengolahan limbah ini menggunakan PVC dan Alkopan, ini didasari karena bahan tersebut memiliki sifat yang tahan terhadap korosi. PVC (poly vinil chloride), polyetena, dan nylon termasuk jenis polimer sintetsis. Polimer sintetis adalah polimer yang dibuat dari molekul sederhana (monomer) dalam pabrik atau polimer yang dibuat dari bahan baku kimia (Ikhsan, 2016). Desain alat dapat ditunjukkan pada Gambar 2 berikut ini.

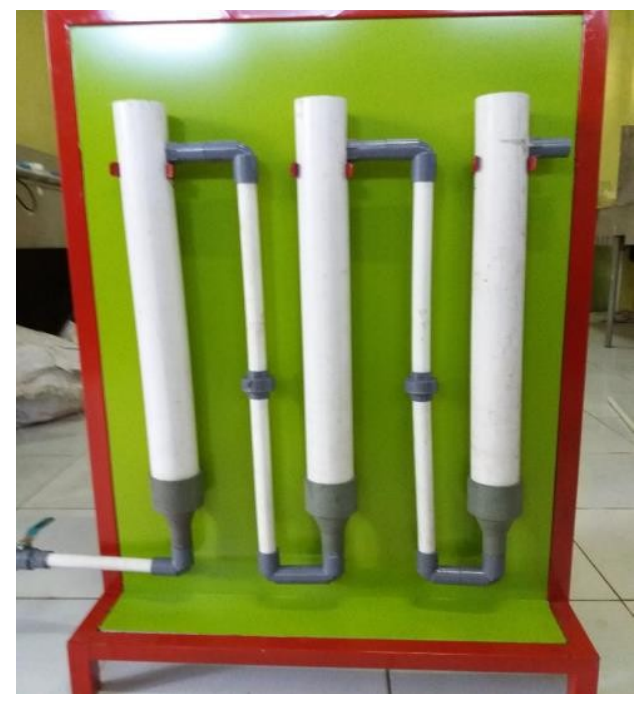

(b)

Gambar 2. (a) Rangka alat pengolahan limbah cair laboratorium dan (b) Reaktor pengolah limbah

Rangka alat pengolahan limbah terbuat dari alkopan dan rangka besi galvanis yang tahan karat. Alucopan sendiri terbuat dari alumnium yang dilapisi dengan plastik, sehingga tahan terhadap cairan yang mengandung zat kimia tertentu. Aluminium Composite Panel (ACP) merupakan jenis aluminum yang ringan, namun material ini dikenal sangat kuat dan warna yang tidak mudah luntur (Anonim, 2015).
Pada penelitian ini, TSS dan TDS mengalami penurunan seiring dengan bertambahnya tinggi adsorben dalam kolom dan mencapai tinggi adsorben optimum pada ketinggian $20 \mathrm{~cm}$. Setelah ketinggian $20 \mathrm{~cm}$ yaitu pada ketinggian $25 \mathrm{~cm}$ dan $30 \mathrm{~cm}$ kembali mengalami kenaikan nilai TSS dan TDS . Kondisi optimum terjadi pada ketinggian adsorben $20 \mathrm{~cm}$ baik nilai TSS maupu TDS. Data penelitian diperlihatkan pada Gambar 3 dan Tabel 1. 
Tabel 1. Variasi ketinggian dengan laju konstan $=6,5 \mathrm{~mL} / \mathrm{detik}$

\begin{tabular}{|c|c|c|c|c|c|c|c|c|}
\hline No & $\begin{array}{c}\text { Tinggi } \\
\text { Adsorben } \\
(\mathrm{cm})\end{array}$ & $\mathrm{pH}$ & $\begin{array}{c}\text { TSS } \\
(\mathrm{mg} / \mathrm{L})\end{array}$ & $\begin{array}{c}\text { Efisiensi } \\
\text { Alat } \\
\text { Terhadap } \\
\text { TSS } \\
(\%)\end{array}$ & $\begin{array}{c}\text { TDS } \\
(\mathrm{mg} / \mathrm{L})\end{array}$ & $\begin{array}{c}\text { Efisiensi } \\
\text { Alat } \\
\text { Terhadap } \\
\text { TDS } \\
(\%)\end{array}$ & Warna & Bau \\
\hline 1 & $\begin{array}{c}\text { Sampel } \\
\text { awal }(0)\end{array}$ & 8,3 & 0,616 & 0 & 0,708 & 0 & Cokelat & Tidak \\
\hline 2 & 10 & 6,5 & 0,228 & 62,987 & 0,656 & 7,345 & Cokelat & Tidak \\
\hline 3 & 15 & 6,5 & 0,220 & 64,286 & 0,644 & 9,040 & Bening cokelat & Tidak \\
\hline 4 & 20 & 6,6 & 0,188 & 69,481 & 0,624 & 11,864 & Bening cokelat & Tidak \\
\hline 5 & 25 & 6,6 & 0,224 & 63,636 & 0,696 & 1,695 & Cokelat bening & Tidak \\
\hline 6 & 30 & 6,7 & 0,228 & 62,987 & 0,628 & 11,299 & Cokelat bening & Tidak \\
\hline
\end{tabular}

Kualitas air meningkat seiring bertambahnya laju alir umpan ditinjau dari nilai TDS dan TSS. Kecepatan optimum terjadi pada laju alir 21,94 $\mathrm{mL} /$ detik dengan nilai TSS sebesar $0,164 \mathrm{mg} / \mathrm{L}$ dan TSS sebesar $0,606 \mathrm{mg} / \mathrm{L}$. Selanjutnya pada laju alir yang lebih besar yaitu pada laju $31,30 \mathrm{~mL} /$ detik dan $72,80 \mathrm{~mL} /$ detik kembali mengalami kenaikan nilai TSS dan TDS, ditunjukkan pada Gambar 4 dan Tabel 2. Warna air umpan mengalami perubahan yaitu dari cokelat menjadi agak bening.

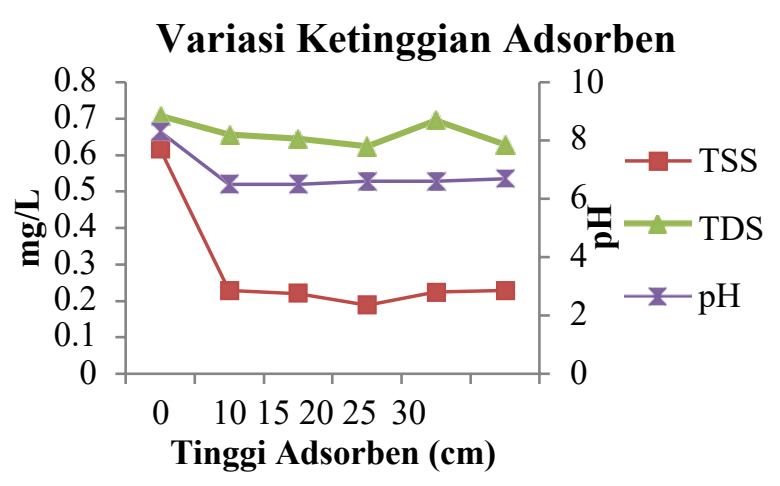

Gambar 3. Pengaruh ketinggian adsorben terhadap nilai TDS,TSS dan $\mathrm{pH}$

Tabel 2. Variasi laju alir dengan ketinggian adsorben konstan $=20 \mathrm{~cm}$

\begin{tabular}{|c|c|c|c|c|c|c|c|c|}
\hline No & $\begin{array}{c}\text { Laju Alir } \\
(\mathrm{mL} / \text { Detik })\end{array}$ & $\mathrm{pH}$ & $\begin{array}{c}\text { TSS } \\
(\mathrm{mg} / \mathrm{L})\end{array}$ & $\begin{array}{c}\text { Efisiensi Al } \\
\text { Terhadap } \\
\text { TSS }(\%)\end{array}$ & $\begin{array}{c}\text { TDS } \\
(\mathrm{mg} / \mathrm{L})\end{array}$ & $\begin{array}{c}\text { Efisiensi } \\
\text { Alat } \\
\text { Terhadap } \\
\text { TDS (\%) }\end{array}$ & Warna & Bau \\
\hline 1 & $\begin{array}{c}\text { Sampel } \\
\text { awal(0) }\end{array}$ & 6,7 & 0,436 & 0 & 0,752 & 0 & Cokelat & Tidak \\
\hline 2 & 2,68 & 6,9 & 0,30 & 31,193 & 0,676 & 10,106 & Cokelat bening & Tidak \\
\hline 3 & 21,94 & 7,0 & 0,164 & 62,385 & 0,606 & 19,415 & Agak bening & Tidak \\
\hline 4 & 31,30 & 6,9 & 0,40 & 8,257 & 0,636 & 15,426 & Cokelat bening & Tidak \\
\hline 5 & 72,80 & 7,0 & 0,428 & 1,835 & 0,668 & 11,170 & Cokelat bening & Tidak \\
\hline
\end{tabular}

Pada penelitian ini, dengan laju alir yang konstan yaitu $6,5 \mathrm{~mL} /$ detik dan tinggi adsorben yang bervariasi diperoleh tinggi adsorben optimum pada ketinggian $20 \mathrm{~cm}$ dengan efisiensi alat terhadap TSS sebesar $69,481 \%$ dan $11,864 \%$ untuk TDS. Tinggi 
adsorben konstan yaitu pada ketinggian $20 \mathrm{~cm}$ dengan laju alir yang bervariasi diperoleh lajur alir optimum pada $21,94 \mathrm{~mL} /$ detik, dimana efisiensi alat terhadap nilai TSS sebesar $62,385 \%$ dan $19,415 \%$ untuk TDS. Faktor yang berpengaruh terhadap penyerapan limbah yaitu jenis zat yang diserap, luas permukaan adsorben, konsentrasi zat yang diadsorpsi dan suhu (Handayani dan Sulistiyono, 2009). Selain itu, perbedaan kecepatan alir umpan serta jenis limbah juga mempengaruhi efisiensi hasil air olahan yang melewati kolom adsorpsi atau reaktor (Marhendra dan Bagastyo, 2017).

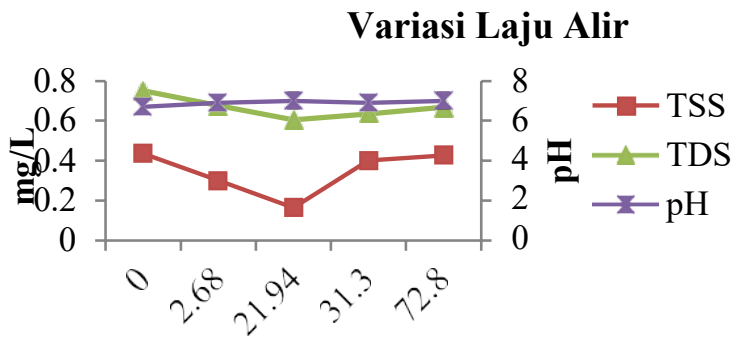

\section{Laju Alir (mL/Detik)}

Gambar 4. Pengaruh laju alir terhadap nilai TDS,

TSS dan $\mathrm{pH}$

Efisiensi penurunan TSS pada limbah domestik dengan menggunakan metode reaktor MBBR(Moving Bed Biofilter Reactor), cukup signifikan dapat mencapai $90 \%$ pada hari ke 18 dengan menggunakan media Kaldness dan telah memenuhi baku mutu

\section{UCAPAN TERIMA KASIH}

Penulis mengucapkan terima kasih kepada Politeknik Negeri Ujung Pandang atas dukungan finansial pada penelitian ini.

\section{DAFTAR PUSTAKA}

Fahruddin. (2017). Pengelolaan Limbah Pertambangan Secara Biologis (Cetakan I). Celebes Media Perkasa. Makassar.

Handayani, M., dan Sulistiyono, E. (2009). Uji Persamaan Langmuir Dan Freundlich Pada Penyerapan Limbah Chrom (Vi) Oleh Zeolit. Ptnbr-Batan, 1(6), 130-136.

Haribowo, R., Megah, S., dan Rosita, W. (2019). Efisiensi Sistem Multi Soil Layering Pada Pengolahan Air Limbah Domestik Pada Daerah Perkotaan Padat
(Kholif dkk., 2018). Efisiensi penurunan nilai TSS pada limbah air asam tambang dengan menggunakan filter biomassa sabuk kelapa mencapai 31,24 \% (Pinandari dkk., 2011). Berdasarkan efisiensi penurunan TSS, reaktor dengan adsorben biomassa kulit buah cokelat lebih baik dibandingkan dengan filter biomassa sabuk kelapa. Reaktor MBBR lebih baik dibandingkan dengan filter biomassa kulit buah cokelat ditinjau dari segi TSS atau berdasarkan parameter fisika.

Warna sebelum dan sesudah perlakuan mengalami perubahan yaitu dari cokelat berubah menjadi cokelat bening dan bahkan agak bening. Dari segi bau, sampel sebelum perlakuan dan setelah perlakuan melewati kolom adsorpsi tidak signikan perubahannya, kondisi normal. Pada laju alir lebih besar $72,80 \mathrm{~mL} /$ detik, kondisi limbah laboratorium dari segi warna tidak mengalami perubahan krn kontak antara adsorben dengan limbah sangat singkat.

\section{KESIMPULAN DAN SARAN}

Desain reaktor memiliki kondisi optimum pada laju alir 21,94 $\mathrm{mL} /$ detik, ketinggian adsorben $20 \mathrm{~cm}$, mampu menurunkan nilai TSS dengan efisiensi sebesar $62,285 \%$ dan TDS sebesar 19,415\% serta pada kondisi optimum memiliki nilai $\mathrm{pH}$ 7. Ditinjau dari segi warna, air limbah mengalami perubahan dari cokelat menjadi agak bening dan bau tidak mengalami perubahan.

Penduduk. Jurnal Teknik Pengairan, 10(No.1), 11-27.

Hartuno, T., Udiantoro, dan Agustina, L. (2014). Desain Water Teratment Menggunakan Karbon Aktif Dari Cangkang Kelapa Sawit Pada Proses Pengolahan Air Bersih Di Sungai Martapura. Ziraa'ah, 39(3), 136-144.

Ikhsan, K. (2016). Karakteristik Koefisien Absorbsi Bunyi dan Impedansi Akustik dari Material Berongga Plafon PVC Menggunakan Metode Tabung Impedansi. Tesis Program Pascasarjana Jurusan Fisika MIPA - Universitas ANDALAS, Padang.

Katherine, dan Arie, A. A. (2016). Desain 
Kolom Adsorbsi Cair Fixed-Bed Untuk Penghilangan Limbah Zat Warna. Laporan PKM,Universitas Katolik Parahyangan, Bandung.

Kholif, M. Al, Sutrisno, J., dan Prasetyo, I. D. (2018). Penurunan beban pencemar pada limbah domestik dengan menggunakan. Al-Ard Jurnal Teknik Lingkungan, 4(1), $1-8$.

Kristaufan, J. P., Purwati, S., dan Setiawan, Y. (2010). Pengolahan Air Limbah Industri Kertas Karton Dengan Up-Flow Anaerobic Sludge Blanket ( Uasb ) Dan Lumpur Aktif Up-Flow Anaerobic Sludge Blanket ( UASB ) And Activated Sludge. Berita Sellulosa, 45(No. 1), 2231.

Marhendra, B. A., dan Bagastyo, A. Y. (2017). Kombinasi Biofilter DownflowUpflow Pengolahan Spiked Pond Water Kombinasi Biofilter Downflow-Upflow. Skripsi, Program Studi Teknik Lingkungan. Fakultas Teknik, Insitut Teknologi Sepuluh November, Surabaya.

Muliyatni, A. S., Budiani, A., dan Taniwiryono, A. (2012). Aktivitas antibakteri ekstrak kulit buah kakao ( Theobroma cacao L .) terhadap Escherichia coli , Bacillus subtilis, dan Staphylococcus aureus. Menara Perkebunan 2012, 80(2), 77-84.

Pinandari, A. W., Noor, F. D., Nugraha, A., dan Suhartono, E. (2011). Uji Efektifitas Dan Efisiensi Filter Biomassa Menggunakan Sabut Kelapa (Cocos nucifera) Sebagai Bioremoval Untuk Menurunkan Kadar Logam (Cd, Fe, Cu), Total Padatan Tersuspensi (TSS) Dan Meningkkatkan $\mathrm{pH}$ Pada Limbah Air Asam Tambang Batubara. Prestasi, 1, 112.

Purnamawati, H., dan Utami, B. (2014). Pemanfaatan Limbah Kulit Buah Kakao ( Theobroma cocoa L .) Sebagai Adsorben Zat Warna Rhodamin B. Prosiding Seminar Nasional Fisika Dan Pendidikan Fisika (SNFPF), 5, 12-18.

Putra, R. S., Trahadinata, G. A., Latif, A., dan
Solehudin, M. (2017). Wastewater Treatment of Chemical Laboratory using Electro Assisted- phytoremediation ( EAPR ). International Conference on Chemistry, Chemical Process and Engineering (IC3PE), 20077(March). https://doi.org/10.1063/1.4978150

Rahmaniah, S. (2016). Penyebaran Taaman Kakao. (Online), (Hhtp://sakinahrahmaniah.blogspot.com). (17 Desember 2018).

Sa, S., dan Abike, A. (2016). Tapping in to The Good Use of Cocoa ( Theobroma cacao ) POD Husks Towards Finding Alternative Sources of Nutrients For Animals in Nigeria . J Food Technol Pres, 1(1).

SNI 06- 6989-3-2004. Air dan Air Limbah Bagian 3. Cara Uji Padatan Tersuspensi Total (Total Suspended Solid, TSS).

SNI 06- 6989-27-2005. Air dan Air Limbah Bagian 27 . Cara Uji Kadar Padatan Terlarut Total (Total Dissolved Solid, $T D S)$ Secara Gravimetri.

http://suksesdinamika.blogspot.com/2015/10/p engertian-aluminum-composite-panelacp.html (13 Juli 2019). 